\title{
Coordenadas geográfico-literarias de la construcción de identidades: El hombre de Montserrat de Dante Liano y La montaña es algo más que una inmensa estepa verde de Omar Cabezas
}

Isabel Avendaño Flores

Escuela de Geografía

Universidad de Costa Rica

Resumen

El hombre de Montserrat (1994), de Dante Liano (Guatemala, 1949), y La montaña es algo más que una inmensa estepa verde (1999), de Omar Cabezas (Nicaragua, 1950) son dos novelas centroamericanas en las cuales la geografía y el espacio literario se relacionan desde el puno de vista de su descripción textual, las metáforas espaciales y el espacio en el texto.

Palabras clave: novela centroamericana contemporánea, espacio literario, campo/ ciudad, poder militar

\section{Abstract}

El hombre de Montserrat (Montserrat'Man) (1994) by Dante Liano (Guatemala, 1949), and La montaña es algo más que una inmensa estepa verde (The Mountain is more than a Huge Green Steppe) (1999) by Omar Cabezas (Nicaragua,1950) are both Central American novels in which geography and literary space are 
related from the point of view of textual description, space metaphors, and space in the text itself.

Keywords: Central American contemporany novel, literary space, country/city, literary power

$\mathbf{E}$ 1 uso de textos literarios para un análisis geográfico es de larga data. La Geografía estudia los sujetos humanos y su organización territorial, mas algunas de sus herramientas reafirman un afán por la localización precisa y por la mensurabilidad de los objetos geográficos. Sin embargo, todo este esfuerzo importante y enriquecedor del quehacer geográfico se enfrenta, aún hoy, por lo menos con dos resquicios de subjetividad muy importantes: uno, abierto por el papel del propio sujeto investigador; el otro, ampliado por la diversidad y número de sujetos investigados y su dinámica de cambios y transformaciones (Carreras, 1998: 163).

El objetivo de estas páginas es incursionar en las relaciones entre coordenadas geográfico - literarias y la construcción de identidades. Aunque, como se mencionó, tales relaciones están atravesadas por la subjetividad del investigador y por la dinámica que envuelve al investigado. Las novelas que serán retomadas son El hombre de Montserrat y La montaña es algo más que una inmensa estepa verde, las cuales son parte de la literatura producida en América Central y que es muy poco conocida:

- El hombre de Montserrat fue editada por primera vez en 1994 por la editorial mexicana Aldus S.A. Su autor -Dante Liano (1949-...)- ha sido calificado por el sociólogo y crítico Arturo Arias como el más fino hilvanador del lenguaje y el más sensible a sus sutilezas, de todos los narradores guatemaltecos contemporáneos. Perteneciente a una generación muy golpeada por la represión en Guatemala de 1978-1985 y a la que le tocó renovar y vitalizar la narrativa de su país de origen a partir del punto en que la dejara Miguel Ángel Asturias (Arias, 1998).

- Por su lado, La montaña es algo más que una inmensa estepa verde fue publicada en 1999 y es la primera novela de Omar Cabezas, nacido en León, Nicaragua, en 1950. Cabezas es parte de una generación que se sumó al proyecto nacional y que propició la Revolución Popular Sandinista (1979-1990).

Con base en lo que Carreras (1998:171) propone, realizar un análisis espacial implica cuatro entradas diferentes de datos: cronológicos, temáticos, por lugares y por personajes. La localización de los lugares y escenas, el planteamiento de los itinerarios, la intensificación de los símbolos, el simple número de citas o la intensidad cualitativa de la acción, son informaciones esenciales que ayudarán a un primer resultado de la lectura geográfica. Además, plantea un amplio espectro de informaciones que podrían reconstruirse de una obra de creación literaria, a saber:

1. Pueden registrarse los datos referentes al autor y a sus propios lugares. Puede 
intentarse establecer si el conocimiento que el autor tiene del territorio que describe o en el que sitúa la acción es directamente vivencial o indirecto. Es importante conocer la época y duración de este conocimiento vivencial, si existe, y la información erudita complementaria que haya podido utilizar para escribir su libro. Con ello se obtiene información acerca de la subjetividad de las descripciones y se obtienen datos importantes para valorar los juicios e impresiones que se transmiten. Junto al conocimiento material de los lugares literarios, hay que intentar también situar la apreciación estética del paisaje que se desprende de las descripciones, que estará relacionada con la formación artística e intereses del autor. Y, finalmente, aunque resulte difícil, debe intentarse conocer cuáles son las ideas científicas que el autor pueda poseer acerca de la Geografía o de las disciplinas que se relacionen con ella.

2. Deben analizarse los datos acerca de los personajes y de los lugares de la acción. Más allá de las informaciones concretas que se desprendan de las descripciones, hay que tratar de captar cuál es el sentido de lugar del autor a partir de sus personajes.

Desde un punto de vista geográfico, se ha clasificado la producción literaria, según el papel que el territorio desempeña en la acción: escenario o simple decorado, ambiente o protagonista total. La mayor cantidad de información se obtiene de aquellas obras en las que el territorio aparece como un ambiente, representando valores, o como exteriorización de los estados de ánimo de los protagonistas o del narrador; se puede desarrollar así, una auténtica gramática del espacio.
Los itinerarios constituyen un verdadero viaje iniciático de los personajes, alcanzando así un gran contenido de valores. Incluso la propia relación de los personajes con el territorio en el que se mueven, el hecho de ser autóctonos o foráneos y sus implicaciones pueden aportar una gran cantidad de información a la interpretación del lugar estudiado.

3. Debe intentarse el análisis de los conceptos generales de espacio y tiempo contenidos y utilizados en la obra. Un primer nivel analítico permite conocer las transformaciones del lugar a través del tiempo, independientemente de su dirección (hacia adelante o hacia atrás, en flash back). La dificultad de captar el tiempo, a menudo obliga a recurrir a la descripción de los cambios de los lugares como expresión de la irreversibilidad. Mayor interés puede alcanzar el estudio de las vivencias del tiempo y del espacio en los personajes, de aquellos cambios y transformaciones y de las diversas mentalidades que aparecen asociadas a ellos. De hecho, el tiempo, el gran desconocido, suele acabar acaparando gran parte del protagonismo de toda obra de creación, al fomentar las descripciones de lugares anclados en el tiempo, como ucrónicos ${ }^{1}$, o la reiteración de un tiempo cíclico, introduciendo la valoración del nunca pasa nada o nada cambia, en realidad. Pocas novelas llegan a poder plantear conceptos más sofisticados del tiempo, pero por su rareza son un objeto de estudio aún más interesante.

1 Ucronía: Reconstrucción lógica aplicada a la historia, dando por supuesto acontecimientos no sucedidos, pero que habrían podido suceder (Diccionario Real Academia Española, 2001). 
4. Obtenidas estas informaciones o incluso para obtenerlas, en muchos casos, es necesario acudir a fuentes de datos complementarias, tales como cartografía topográfica y los planos de la época en que transcurre la acción, enciclopedias y tratados de literatura, atlas, libros de viajes, diccionarios geográficos, estadísticas y obras de geografía regional. Sólo con estas y otras informaciones paralelas, se estará en condiciones de realizar una evaluación del sentido y valor de las informaciones obtenidas que permita llegar a las necesarias conclusiones de cualquier trabajo científico (Carreras, 1998:173-175).

Asimismo, en la relación geográfico-literaria, Bailly (1998:29) sintetiza los grandes principios definitorios de la Geografía y que en estas páginas estarán implícitos. Como podrá deducirse, estas geografías se basan en representaciones en el sentido "creación social o individual de un esquema pertinente de la realidad", lo que permite abordar el espacio en sí y el sentido del espacio. Esta geografía, consciente de su subjetividad, analiza a la vez los discursos y las prácticas espaciales, con el fin de descifrar de ellos, representaciones, coherencias y repeticiones; incluye las representaciones razonadas y las de aquellas personas que experimentan sentimientos $y$ se apegan a sus lugares de vida.

- El principio existencial: los geógrafos centran su interés en los hombres en sociedad, pero ellos a su vez forman parte de sociedades de cuyas ideologías son el reflejo. De ahí la necesidad de explicitar las ideologías y los conceptos con los que se explora el conocimiento.
- El principio de representación: el espacio no constituye el objeto de estudio, ya que la realidad objetiva es inexistente fuera de nuestras construcciones. El conocimiento geográfico se basa en la representación de fenómenos a partir de conceptos; la geografía no es la ciencia de los paisajes, sino más bien de los signos que ella interpreta.

- El principio imaginario: toda proposición geográfica es una imagen, es decir un modelo simplificado del mundo o de una parte del mundo (regional o temático).

- El principio de creación: la representación es una creación de un esquema pertinente, pero parcial, de un proceso o de un espacio, que nos remite a nuestras ideologías y a la manera de estructurarlas.

- El principio de retroacción: las representaciones se alimentan de las prácticas y a la inversa. Así, una sociedad que crea su medio de vida no lo hace únicamente a través de sus relaciones de producción, sino gracias a las representaciones (ideología, valores) propias de esta sociedad.

En este nivel, los conceptos "lugar" y "territorio" adquieren todo su sentido, ya que no son sólo forma material de la organización social del espacio, sino que el territorio es portador de ideologías, de representaciones simbólicas y, también, del inconsciente. El estudio de la territorialidad, a la vez real e imaginaria, se convierte en el objeto mismo del enfoque geográfico. $\mathrm{Y}$ en este terreno, 
nadie puede olvidar que la territorialidad es en sí misma una imagen del mundo, subjetiva, evolutiva.

Para Bajtín (2000:165, 166), vivir quiere decir participar en un diálogo: preguntar, poner atención, responder, estar de acuerdo. En este diálogo, el hombre completo toma parte con toda su vida: con sus ojos, labios, manos, alma, espíritu, el cuerpo entero, los actos. En este sentido, la literatura crea las imágenes muy específicas de las personas, en las cuales el yo y el otro se combinan de un modo especial e irrepetible: el yo en forma de otro, o bien el otro en forma de un $y o$.

\section{Las novelas como espacios geográficos: descripciones}

Las características de un espacio geográfico como su concreción, dinamismo espacial y temporal, el hecho que pueda ser descriptible, percibido y vivido, también las posee una novela. La analogía novela - espacio geográfico puede tener diversos prismas e innumerables concatenaciones, no obstante en esta sección apenas se mencionarán algunas.

El hombre de Montserrat: Su topónimo puede clasificarse como de pragmatopónimo, es decir, que el motivo que dio pie para el título de la obra recuerda o conmemora un hecho: el cadáver encontrado en un lugar llamado Montserrat. De por sí, la denominación Mont(monte)-serrat tiene un origen etimológico doblemente geográfico.

El paisaje o apariencia da cuenta de una novela bélica. Así, la portada es un detalle de un arma bélica en plena acción y la contraportada trae en detalle el cañón del arma disparando.

En las solapas de la portada y la contraportada se brinda al lector la fuente de inspiración del autor para escribir: "en una ciudad de cualquier región del cono sur de América, un militar encuentra el cadáver de un hombre". Asimismo, se dan algunas pautas que la obra debería reflejar: el mundo en que se debate la miseria y ceguera del sector militar que ha accedido al poder por la vía de la violencia; las imposibilidades, malestares y derrotas de las clases medias -con su barniz de modernidad-; y las sombras de los condenados de la tierra, víctimas de las circunstancias: las "minorías étnicas" ${ }^{2}$, los indios, inmovilizados por una estructura económica y social construida y sustentada por los intereses foráneos aunados a los domésticos de los grupúsculos privilegiados. En la extensión de la contraportada, aparece un breve currículo de vida del autor.

La montaña es algo más que una inmensa estepa verde: El topónimo es una combinación de orónimo, es decir que la montaña adquiere prácticamente un nombre propio, es un territorio con una carga de sentido que lo da el "es algo más que" y de corónimo, ya que se refiere a una determinada región, la montaña.

En América Latina, los sistemas montañosos desde México hasta el cono sur, han remitido a grandes civilizaciones e importantes organizaciones políticas. En las altitudes inferiores a los 2000 metros sobre

2 Llama la atención el entrecomillado, es archiconocido que en Guatemala un alto porcentaje de la población está compuesto por indígenas. 
el nivel del mar, aproximadamente, es el dominio cálido y húmedo, donde el paisaje de base es el de la selva tropical siempre verde. Siguiendo con el título de la obra ¿qué se entiende por estepa? Es la zona compuesta de hierbas bajas, con ausencia de árboles y matorrales, pero se pueden encontrar dentro de la misma región, áreas boscosas y arboladas, sobre todo, en el fondo de los valles. Algunas veces, gran parte del suelo permanece descubierto. El suelo muestra una deficiencia hídrica, que varía de acuerdo con la estación del año, lo cual afecta el crecimiento de las hierbas. La estepa en medios secos transita al semidesierto y en medios lluviosos, a la pradera (Strahler y Strahler, 1992).

A primera vista, el título de la obra encerraba una contradicción. No obstante, transcurrido un buen tramo de la novela, Cabezas expresa que el primer día de su proceso en la montaña:

no era selva, sino pinares, cerros de pinos, ya bastante diezmados por las compañías madereras norteamericanas; al revés de ser una vegetación espesa y tupida, era una vegetación sumamente rala, casi como estar haciendo escuela en un parque al descampado, teníamos que camuflar p. (172)

En la segunda edición (1999), la portada de color verde muestra un dibujo de un hombre campesino con un arma, acompañado de un (a) niño (a) y atrás de ambos, una montaña que se asemeja más a un volcán, con las abreviaturas del Frente Sandinista de Liberación Nacional y un fragmento del techo de una casa construida de tejas que transporta a la época colonial o a las primeras décadas independentistas. Existe un marco en la portada, con algunos símbolos indígenas como el maíz. Destaca el texto de la contraportada, el cual advierte a la lectora que la obra constituye un libro paradigmático para la revolución nicaragüense. La solapa de la portada trae una breve historia de vida de Omar Cabezas y la de la contraportada, carece de textos.

De igual forma que político-administrativamente, ambas novelas presentan una jerarquía territorial. Dichas categorías poseen status diferentes, extensiones variables, dinámicas distintas. De tal manera, en El hombre de Montserrat, la novela se fracciona en dos categorías, cinco capítulos y, a su vez, en varios apartados. Excepto por el primero que contiene 16, los restantes tienen entre 9 y 11 apartados. En La montaña es algo más que una estepa verde la subdivisión interna es más sencilla, implica únicamente capítulos de extensiones parecidas.

Ambas conforman un espacio en que sus subdivisiones se diferencian por un número ya que ninguno, ni capítulos ni apartados poseen nombre (título). En la primera obra, los límites internos que marcan las unidades no son líneas fijas sino que se comportan como zonas fronterizas, en el sentido que una sección lleva a la otra, una sección se apoya en la otra; son zonas de contacto y la independencia de los apartados es muy discutible. Al final, hay un epílogo que funciona como centro, pues allí se ponen las cosas en orden, se recapitula... se resuelve el misterio. En la segunda obra, aunque hay un hilo conductor, cada capítulo está bien definido y en las últimas 
páginas se ofrece un apropiado glosario de términos y expresiones.

Dentro de los territorios anexados, que dan identidad a las novelas, en la obra de Liano figuran tres paratextos en la página 7: El primero, presentado en francés, es un extracto de Memorias de Adriano de M. Yourcenar, aludiendo a que lo que se cuenta es lo que no figura en las biografías oficiales o lo que no queda inscrito sobre las tumbas. El segundo, es un segmento de Vallejo con Cuídate de España de tu propia España haciendo referencia a cuidarse de la víctima, del verdugo y del indiferente a pesar suyo. $\mathrm{Y}$ el tercero, presentado en italiano de Primo Levi, I sommersi e i salvati.

En la de Cabezas, también en la página 7, como un mapa que ubica a la lectora en el tiempo y el espacio, se expone una dedicatoria a la dirección del Frente Sandinista de Liberación Nacional. En la página 9, Cabezas reconoce la importancia de varias personas en la elaboración del libro, algunas pertenecientes al grupo de los escritores nicaragüenses e identificadas con la revolución.

En cuanto a otros rasgos identitarios, la novela de Dante Liano constituye una mezcla varios niveles discursivos, recursos y temas. Sobresale la intriga, la trama policíaca y la ironía. Cuenta el autor en una entrevista realizada en 1997, que al "salir" de Guatemala, al darse cuenta de su condición de extranjero quiso transmitir su identidad de guatemalteco utilizando un modo de escribir mediado de las novelas policíacas, las cuales devora desde muy joven.

En Cabezas, nunca existió intención política alguna para transmitir sus relatos sobre la revolución. Constituye un testimonio, una realidad de vida narrada con el lenguaje cotidiano del nicaragüense. Estos elementos extratextuales han sido considerados como inductorios para crear credibilidad o veracidad. Tras una petición para grabar su testimonio éste quedó plasmado en la obra, la cual en 1982 ganó el Premio Casa de las Américas. Pese a la controversial clasificación del género novelesco "testimonial", La montaña... ha sido clasificada como una novela testimonial-autobiográfica. En todo caso, yacen en estas dos obras, dos intenciones con diferente fuerza.

\section{Los movimientos espaciales del texto: identidades}

Las manifestaciones de identidad espacial, las imágenes, los tópicos y las metáforas más corrientes que en un tiempo dado marcaron la interpretación del espacio geográfico, son un tanto diferentes para las novelas en estudio.

Mackenbach (2002), con base en otros estudios que analizan la geografía literaria, argumenta que existen tres planos del espacio literario:

1. La descripción textual de espacios físicos que remite a un mundo material fuera del texto: Alude a la diferencia entre un espacio literario (real, físico, concreto) y las concepciones extraliterarias de espacio de un individuo o un grupo de individuos.

2. El uso de metáforas espaciales que describen espacios físicos y la semantización espacial de conceptos abstractos. Implica el uso de metáforas 
espaciales utilizadas de manera múltiple para describir y expresar cosas o sucesos no espaciales.

3. El espacio del texto: Hace referencia a cómo la lengua/un texto describen y representan espacios físicos y metafóricos y cómo el texto mismo constituye un espacio. Se recurre al concepto de "espacio vacío" y se destacan dos procesos de generación de sentido por el lector:

a. el entendimiento de alusiones y relaciones, es decir, la combinación y unificación de dos descripciones textuales separadas por el lector, $\mathrm{y}$

b. complementar alusiones y suplementar significados no denominados en el texto. El texto es creado y recreado nuevamente por el lector, en el contacto intersubjetivo lectortexto. De tal manera, el texto se vuelve dinámico y generativo.

Mackenbach (2002) también menciona que pueden hacerse pesquisas de los diferentes lugares del texto propiamente dicho, es lo que se denomina "literatura de viaje", la cual inspecciona los espacios intratextuales. Enumera cuatro lugares paradigmáticos: la salida/despedida, el punto o momento culminante, la llegada y el regreso. Sin embargo, Mackenbach (2002) argumenta que es mucho más interesante estudiar la dinámica y el movimiento en que están ubicados estos lugares y qué movimientos causan. Así, distingue cinco tipos básicos: el círculo, el movimiento pendular, la línea, la estrella y el saltar.

Con base en lo expuesto, en Liano se parte de los acontecimientos ocurridos en la ciudad; luego, el texto nos transporta a la frontera, después a la selva y, finalmente, el autor nos devuelve con el personaje a la ciudad; por tanto, tenemos un movimiento triangular. Y la novela inicia su relato cuando el personaje principal encuentra un cadáver a la orilla de la carretera y termina con el tropiezo con otro cadáver, por lo cual, es un movimiento circular. A grosso modo, en Cabezas, la novela comienza en la ciudad de León, la mayoría del texto se desarrolla y termina en la montaña.

\section{Movimiento lineal}

En el primero predomina una representación del espacio urbano y, en el segundo, de un espacio rural-la montaña-. En el primero, en el discurso priman los acontecimientos urbanos y dejan en segundo lugar, los de la ciudad. Totalmente al contrario, en Cabezas hay eventos de carácter importante que se desarrollan en León, pero que la montaña es el sitio mítico formador y reformador del hombre nuevo, de los hijos de Sandino. Nuevamente, dos dinámicas textuales diferentes y que a lo largo de estas páginas volverán a mencionarse. 


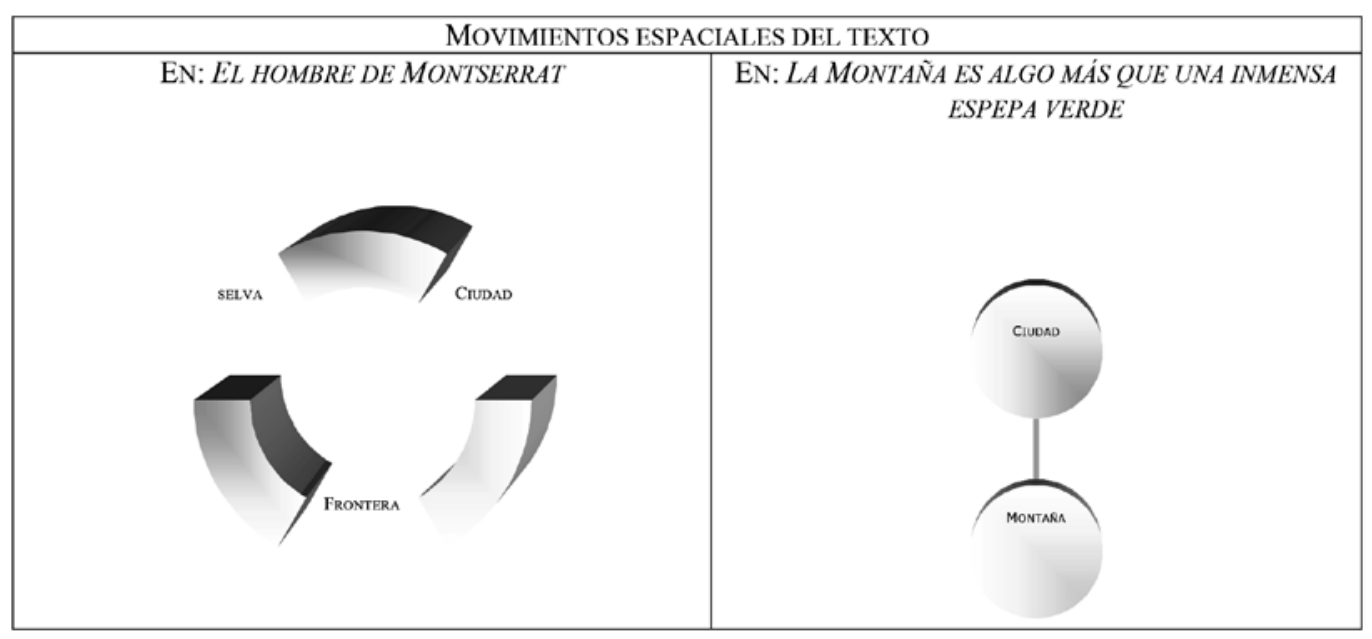

\section{Territorio e identidades representadas}

\section{Territorialidad nacional, regional o local}

Marcar el territorio corresponde a una noción desarrollada en los estudios sobre conducta animal. Mas, denominar y recorrer llevan hacia el territorio, como entidad fundamental del microcosmos y la macrovisión. Dicha macrovisión del mundo pasa por el microcosmos afectivo desde donde se aprende a nombrar, a situar, a marcar el mundo que comprendo desde afuera hacia adentro, como desde adentro, desde el interior psicológico o los interiores sociales de mi territorio, hacia el mundo como resto (Silva, 1998:48). Un mecanismo utilizado, en el caso de las personas para marcar el territorio, es el lenguaje; nos dice Bajtín (2000: 166) que el lenguaje es el territorio compartido por el yo y el otro.

En El hombre de Montserrat no se especifica la ciudad donde se desarrollan los acontecimientos y el relato pudo suceder o efectuarse en cualquier país latinoamericano, pues es de sobra conocido que
América Latina se ha caracterizado por un período de intensa inestabilidad política. No obstante, con cierto riesgo pero segura de que haría una lectura posicionada, partí de la premisa de la nacionalidad del autor, por tanto, él haría referencias a la situación de su país, Guatemala. De tal manera, el punto de referencia extraliterario es Ciudad Guatemala, aunque la territorialidad está explícita.

Contrariamente, en el caso de La montaña es algo más que una inmensa estepa verde, desde un inicio el autor da como punto de referencia la ciudad de León. Y, desde que comienza la obra, el lector sabe que se trata de los eventos relacionados con la lucha política del sandinismo y su organización. Cabezas es muy enfático en una geografía local más que regional o nacional.

No obstante, en Liano en el primer apartado del segundo capítulo, el narrador ubica territorialmente al lector, de la manera siguiente:

Al llegar a un semáforo, se estiró para sacar los anteojos oscuros de la 
guantera: el sol ya estaba pegando y no eran las ocho de la mañana. Así es el Valle de la Virgen. Amanece a las cinco y la niebla se levanta sobre todo alrededor de los barrancos y hay un frío húmedo, intenso, que hace a la gente salir para el trabajo con suéter que dos horas después se vuelve insoportable (p. 41)

En este fragmento, se describen procesos y fenómenos geográficos. Primero, el pasaje se refiere a un país tropical; segundo a que las diferencias de presión barométrica entre valle y ladera provocan que a ciertas horas de la mañana, la humedad se concentre en el valle. Conforme el calor baja al fondo del valle, éste se calienta y de ahí que se refiera al ambiente insoportable. Páginas más adelante, hace menciones a la posición del sol, por ejemplo, en "lo alto", aspecto que confirma esta premisa. Por cierto, un clima óptimo es inexistente; por tanto, la expresión indica una subjetividad inevitable respecto al ambiente y aparejada a otras vivencias.

Tercero, el fragmento menciona el Valle de la Virgen. La ciudad de Guatemala, un punto sobre la cordillera volcánica (al sur del país), ocupa un hermoso valle intermontano drenado por el río Las Vacas, situado aproximadamente a 1500 metros sobre el nivel del mar. A este valle le se asignó su topónimo en 1620, en honor a la Virgen de La Asunción, patrona de la ciudad de Guatemala.

De acuerdo con Bajtín (2000: 6,8) una identidad se define como posición en relación con una geografía, con un espacio social y ecológico particular. Como primer paso, nombrar el territorio es asumirlo en una extensión lingüística e imaginaria; en tanto que recorrerlo, pisándolo, marcándolo en una u otra forma, es darle entidad física que se conjuga, por supuesto, con el acto denominativo (Silva, 1998:48).

El teniente García y el asesor extranjero, junto al jeep del general. Éste dio la orden de ataque. A sus palabras, siguió un silencio plúmbeo, en el que se podía oír hasta el color azul del cielo que se extendía sin nubes en ese día de sol.

Se podía oír el viento, fresco en la zona colinar, que entraba suave entre las plantas, y las mecía, y tocaba sin ofender el rostro de la gente. Se podía oir la vida de la tierra, que bajo los pies no dejaba espacio sin germinar, tal como todo se oye en los cementerios, lejano, pacífico y ajeno a la angustia que muerde las entrañas (p. 54)

De tal manera que, como construcción, la identidad está sujeta a permanentes adaptaciones que se originan en el punto de confluencia o interacción entre lo considerado "propio": el "nosotros" y un contexto exterior: los "otros".

\section{El paisaje y los imaginarios urbanos}

Es muy interesante cómo, en ambas novelas, a la lectora se le transporta tanto por pasajes urbanos como rurales. Sin embargo, son desarrollados de manera muy diferente. En primera instancia, la novela de Liano tiene como escenario el medio urbano, la cual corresponde a la nueva dinámica de la 
narrativa en la presentación del espacio y las identidades en América Latina y, a su vez, a los acontecimientos demográficos y urbanísticos de la región. América Central ha mantenido, a lo largo de los últimos 50 años, índices muy acelerados de crecimiento poblacional y urbanístico.

Por otra parte, desde los años de la década de 1930, los países del istmo estuvieron sometidos a la crisis económica mundial, bloqueando los tímidos ensayos democratizadores y dando apertura a las entronizadas dictaduras personales de militares con firme apoyo de las oligarquías tradicionales, que duraron muchos años, hasta que, a finales de la década de 1940, a la par de la modernización económica, se dieron reformas democráticas. Cuando el modelo de desarrollo mostró sus debilidades, se produjo una vuelta al autoritarismo, menos personalizado pero más represivo aún que el de las viejas dictaduras. En este sentido, tanto la novela de Liano como la de Cabezas, encajan en narrativas de lucha política.

El hombre de Montserrat es una novela que se desenvuelve en el ámbito urbano; sin embargo, hay un escenario con una ambigüedad espacial pues el personaje principal se mueve de tal forma que el mapa mental se muestra a la lectora como imbricado. Es como un "no lugar" desde la óptica del antropólogo Marc Augé, mientras que en Cabezas hay un sentido de pertenencia muy arraigado. No cabe duda alguna de que en las dos obras se entrevén las todavía existentes dicotomías entre urbano y rural, profundamente esquemáticas y engañosas.

El mundo urbano y el rural se han encontrado, se han peleado y, de alguna manera, hoy no sólo coexisten sino que se fecundan y se transforman. Cabezas sostiene lo que Dante Liano fractura, la histórica oposición entre pueblo y ciudad, como dos modos de habitar, de ver, de vivir, de sentir, de sufrir, de gozar, en el eje de lo elemental versus la complicación y el artificio, y de lo auténtico versus lo mentiroso y hasta lo traicionero.

En El hombre de Montserrat, la mayor parte de la novela se desarrolla en la ciudad de rango superior, en el Área Metropolitana de Guatemala, la cual concentra el centro poblacional y el poder político, administrativo y económico más importante del país.

La novela alude a un proceso de urbanización que se ha plasmado en el contexto de un débil desarrollo de las clases medias, tanto en el plano social como en el político. Las oportunidades de los sectores medios son básicamente urbanas e influyen en el crecimiento del aparato institucional del Estado. La movilidad social, el consumo de prestigio, la visibilidad pública del status adquirido, entre otras, son expresiones de la vida urbana que conllevaron al surgimiento de colonias residenciales y los sectores medios que se proletarizan van quedando en las zonas subcentrales deterioradas. Por otro lado, la expansión política es esencialmente urbana: los partidos son los que aglutinan a empleados públicos, pequeños comerciantes, profesionales, etc., y generan típicos fenómenos de populismo de base urbana. Además, la urbanización se ha dado en el seno de una estructura social caracterizada por una fuerte estratificación social (Alvarado, 1988: 115-117). 
La segregación social, política y territorial, la estratificación, el consumismo, la ironía en los topónimos de las zonas residenciales, lo efímero de la posesión de objetos, de cómo vive un país en que impera la violencia, la misma segregación, son factores desventajosos y que dan luces del desenvolvimiento actual de las ciudades (cfr. p. 131 y 85 de la novela).

En otro sentido, en la novela se menciona el típico ambiente urbano actual: embotellamientos, desniveles, semáforos, publicidad, ansiedad, el lento tráfico en "horas pico". Se hacen alusiones a cómo las ciudades son el lugar de la informalidad urbana: durante el día numerosos comerciantes tratan de ganar el sustento diario con su negocio ambulante, como la venta de periódicos. También cómo las personas se incorporan como fuerza laboral desde muy temprano; así los niños deben trabajar, son mano de obra barata, muy poco calificados pues engrosan el sector de deserción escolar. El narrador describe con detalle el trabajo de un niño lustrador, entregado a su labor aunque muy sumiso: “...como un perrito..." (p. 67).

Se demuestra que por las calles todos se mueven con miedo pero también transporta a la lectora a la miseria tan grande y en aumento que se vive en nuestras ciudades, donde la mayoría de las familias se encuentran por debajo de la línea de pobreza y sufren las consecuencias de la exclusión económica y social. Considerando estos aspectos, El hombre de Montserrat constituye un lamentable espejo de la realidad.

¿Qué imagen de la ciudad se puede construir a partir de la novela? Se construye, sin duda, más sobre la base de significaciones como símbolos, rótulos, Montserrat (sitio donde García encontró el cadáver), transeúntes, funciones administrativas, culturales, comerciales que con arreglo a las formas de la estructura. Nombres de calles -Macedo-, desniveles de las carreteras, puentes, parques -Montúfar- nombrar las zonas según su numeración son puntos de referencia de García construidos por sus constantes itinerarios. Aunque es la experiencia individual, García devela con la identidad de cualquier urbanita con una imagen parcial de la ciudad, con su propio sistema interno de referencias que, por supuesto, está relacionado con la familiaridad. Sin duda alguna, la estructura urbana no es la única que interviene; igualmente lo hace el sujeto mismo con diferencias de interpretación acordes con el sexo, el status socioeconómico, el lugar de residencia y la permanencia residencial en la ciudad (Bailly, 1979: 34,35).

¿La identidad de Ciudad Guatemala? Si bien todo espacio urbano viene caracterizado por cierto número de elementos que le son propios y que componen su personalidad, estos mismos elementos que se mencionan en la novela nos permiten identificar Guatemala respecto a otras ciudades, lo que le es propio: su identidad. Por ejemplo, las zonas residenciales llamadas "colonias" o subdividir el espacio por "zonas"; dos aspectos en que capitalinos podrían diferenciarse, "nosotros" los costarricenses de "ellos", los guatemaltecos.

En el marco de los imaginarios espaciales y de la concepción del espacio subjetivo, las imágenes y las percepciones mentales están formadas de elementos espaciales 
memorizados como por elementos simbólicos. La percepción es un proceso activo y creativo. Las personas tratan de identificar determinados elementos, dan prioridad a ciertas dimensiones o estímulos y determinan asociaciones. El espacio es tanto un producto de la estructura del paisaje como del resultado de la actividad y de la experiencia perceptiva del sujeto (Bailly, 1979: 32, 33).

En La montaña es algo más que una inmensa estepa verde, las dos primeras palabras con las que inicia Cabezas el segundo capítulo de su novela, "Mi pueblo...", connotan un sentido de lugar o de pertenencia muy arraigado. Los pasajes urbanos que el autor nombra corresponden a León, capital colonial y del país hasta 1855. Tradicionalmente es considerada el centro cultural e intelectual de Nicaragua; en la actualidad, es la segunda más poblada con más de 100000 personas.

Es caracterizada por Cabezas como una ciudad con un clima sumamente cálido y enfatiza sobre esta percepción, con una gran segregación socioterritorial, donde la burguesía vive en el casco urbano, en el centro pavimentado. El comercio a la ultranza antigua -colonial-, con unas funciones que permiten la interacción humana como lo es el billar de Lezama, el comercio de Prío o el Parque Central, al cual bajo un árbol que diera sombra, la gente se sentaba a platicar en el zacate -césped.

Las insinuaciones en que Cabezas envuelve a la lectora, dejan un sabor de la ciudad que hemos perdido. Es todavía la ciudad de intercambios sociales, en que abunda la solidaridad aunque también es clara la alusión de la ciudad como un lugar de organización política. Los sindicatos, las fogatas que iniciaron en León, en el centro, posteriormente se fueron expandiendo como una mancha, cuenta Cabezas:

La fogata se fue generalizando en todos los barrios y paulatinamente fue adquiriendo un carácter de subversivo... las fogatas eran enemigas de la Guardia. La Guardia odiaba las fogatas porque la fogata concentraba a la gente. El fuego concita, integra, une... la fogata fue creciendo... se convirtió en un abierto desafío, en una conspiración pública... en un grito... en consigna... Era un pueblo en llamas que posteriormente se convirtió en un pueblo en armas. (Cabezas, 1982: 58-59)

Por otro lado, Cabezas nos presenta un espacio urbano nocturno en el que el tráfico de personas y la movilidad "ilegal", a escondidas, en secreto, con un alto rasgo de misterio, son comunes.

\section{El paisaje y los imaginarios rurales}

Cada vez es más difícil defender un concepto unívoco de ciudad y una clara diferenciación entre lo rural y lo urbano. La idea de un continuum rural/urbano parece ser más adecuada que la tradicional separación campo-ciudad. Desde este punto de vista, hay aspectos interesantes que discutir en ambas novelas.

Dentro del imaginario en El hombre de Montserrat, el narrador describe el sentimiento de una ruralidad idílica; una concepción artística respecto a la urbe. Muy sutilmente, breves frases llevan a una 
lectura relacionando medio rural y raíces étnico-históricas; una forma tradicional de escritura de la literatura en general y hoy que el espacio rural se urbaniza y la ciudad se ruraliza, esta división tajante es del pasado, de un pasado romántico.

Pasaron las casas bajas, coloreadas, como de pastillaje, de las afueras de Amatlán y agarraron camino para Ávila. Infinitas tonalidades de verde. El verde claro de la grama que nacía en ensenadas tibias como respiración adormecida, el verde confundido con el amarillo de las cañas que sobresalían de los arroyos transparentes que en la costa se hacían ríos turbulentos; el verde geométrico de los campos de trigo; el verde perico de los árboles cercanos; el verde umbroso de las ramas bajas; el verde-verde profunda respiración verde del viento que se colaba como podía entre el alma de los bosques; el marrón verdeado de los troncos de los árboles; el verde azulado de las manchas boscosas de las montañas lejanas; el verde negro de la oscuridad en donde las tupidas ramas no dejaban llegar el sol. Y había caminitos por donde uno hubiera querido dar un timonazo y perderse allí y no salir jamás, como si esos senderos llevaran a un mundo nuevo en donde reinase la paz profunda de los bosques verdes y majestuosos, caminos como una serpiente de plumas verdes.

Del fragmento destacan el encanto por el campo, así como la alusión a la serpiente cubierta de plumas verdes, al quetzal por antonomasia (en maya al Quetzalcóalt, Gucumatz), parte de la herencia maya.

Por otro lado, al finalizar la novela, durante el tiempo en que García estuvo en la selva, el narrador omnisciente describe el romance que tuvo con la Maríta y habla de la cantidad y tipo de productos que se expendían en su pequeño negocio, mientras su marido estaba afuera en labores agrícolas -desboscando una parcela-, mostrando la importación de elementos de la ciudad (consumo de coca cola, compra de medias para esta mujer), así como que en las zonas rurales hay numerosas aldeas campesinas en que la población convive en situación de precariedad. Desde el marco de referencia de García, estaríamos ante identidades construidas en el medio urbano frente a aquellas de la ruralidad, cada una con sus vicisitudes. En el viaje a la frontera, el espacio rural impregna fuerza, identidad, pero cuando debe vivir en la selva, es inexistente la identificación de García con ella, pues semánticamente, la selva es el lugar del destierro, del exilio y de la absurdidad de la actividad militar que por momentos abomina y ama. De modo tal, Dante Liano maneja la construcción identitaria desde dos prismas.

En La montaña es algo más que una inmensa estepa verde, es muy fuerte la dicotomía entre el campo y la ciudad. Es claro que el activismo social se extendió de las ciudades al campo y su combatividad se convirtió en un factor determinante del escenario político. La transformación del papel de las regiones como promotoras del cambio social fue muy importante y sumamente notable, según expresa Cabezas. 
Si se define la identidad como la fuente de sentido y experiencia para la gente, la fuente de sentido en la novela está enfocada hacia la creación de un hombre nuevo. Y la fuente de experiencia está sentada en el autorreconocimiento colectivo, el cual es una fuerza que interviene en el proceso identitario. Así se deduce un 'nosotros'-los que siguen el sandinismo- contradictorio: hombres duros, curtidos -con experiencia-, fraternales, muy sensibles, tiernos, humildes aunque se trataran toscamente, sin egoísmos, ni mezquinos... formados y reformados en la montaña. “... Ahí nace el hombre nuevo en la montaña...”.

Tan importante es el tema de la ruralidad en la novela que la identidad individual y la colectiva están relacionadas íntimamente con la montaña, no como otras basadas en categorías personales como nación, sexualidad, clase, género, religión y etnia. La montaña y el medio geográfico juegan un factor esencial en el autorreconocimiento y la contrastación con los otros. El lodo, la lluvia, la montaña los han moldeado como grupo. El espacio geográfico "nos” lavó, -tal y como dice Cabezas, un montón de taras de la sociedad burguesa que representan vicios. Además de la posición de clase subyacente, el medio geográfico juega un papel importante como soporte material para la concreción de las prácticas cotidianas. Existe una construcción de la identidad utilizando materiales de la geografía para la purificación.

La montaña ocupa un papel determinante, se personifica. Semánticamente, el espacio se vuelve una figura femenina mítica:
... A veces me salían ganas de decir: mirá montaña, si vos sos piedra y vegetal inanimado, vos aquí no pintás nada, vos aquí no discernís; porque a mí me daba la impresión de que ella empezaba a discernir, empezaba a pensar, como que una fuerza interna hacía que ella pensara y que tomara partido y discerniera... ¿a cuenta de qué esta cabrona? Yo tenía ganas de decirle: mirá, aquí vos no pintás nada... Vos sos aquí vegetal, vos sos roca, vos protegés aquí a quien se te meta; porque yo llegué a pensar que ella protegía a la Guardia, que ella tenía que ver algo con los signos de los tiempos, y que los signos de los tiempos los agarraba ella a favor de la Guardia, a favor de lo estatuido...

La equipara con una mujer, madre, protectora, amorosa, razonadora y amante leal:

... Y como que ella se persuadió de lo que yo decía, y de lo que yo pensaba,... después de la muerte de Tello, que a lo mejor, no sólo para mí sino que también para la montaña era un símbolo... porque vivía con ella... tuvo relaciones con ella, le parió hijos, entonces la montaña cogió a Tello como la medida de las cosas y cuando Tello muere, ella siente que se va a acabar. La montaña siente que ya no tiene ningún compromiso, que lo demás es babosada... Pero cuando ve la disposición de combate del grupo de hombres marchando ahí, sobre ella, en el corazón de ella, como que siente que Tello no es el fin del mundo, ni sus comienzos... 
Que Tello fue su hijo, aunque haya sido su vida... un amante secreto... su hermano, su animal, su piedra, aunque Tello haya sido su río. Ella se tuvo que dar cuenta que Tello no era el fin del mundo. Ella tenía que darse cuenta que...

La montaña más que dar origen al nombre de la obra, es un espacio, un lugar, aquel que forma esa identidad individual extrapolada a la colectiva y en la que los sandinistas son la "otredad" de lo estatuido. Formarse en la montaña representaba: “... nos sentíamos frente a la historia, de pecho, a conquistar el futuro, el mundo...". Hay una alta dosis de sincretismo, donde se mezclan valores cristianos con animismos; un antropomorfismo asignado a la "mole verde". Así, hay una fuerte creencia en que la montaña tiene alma, espíritu; es un ser sobrenatural.

Según Gaínza (1988:53-58), "no hay identidad sin una herencia, no hay identidad sin una proyección", de tal manera que Cabezas construyó las raíces de su identidad en la montaña de la herencia que dejó Sandino. Los principios del Frente Sandinista han resaltado el modo de ser del nicaragüense: "estos principios no eran nuevos, no los había inventado el FSLN, sino que ésa era un patrimonio histórico, era un tesoro que íbamos a desenterrar". Cabezas procesó materiales y los reordenó en su sentido, según las determinaciones sociales y los proyectos culturales implantados en su estructura social y en su marco espacial / temporal. La proyección será la construcción de un "hombre nuevo", que no parte de cero sino con tradición histórica. Mediante la lucha era una vuelta a la dignidad.
El proyecto enraizado en Sandino supone una elaboración nacionalista y antimperialista. Argumenta Gould (1995:261) "Sandino estaba construyendo un discurso de nacionalismo popular, una Nación alternativa., o sea él esta 're-inventando la nación' ya que Nicaragua se había convertido en "patrimonio de oligarcas y traidores" o sea, proponía un nacionalismo alternativo al proyecto de las elites políticas". Sandino tenía una visión "racial" de la América indo-hispana, profundamente mestizada; refutaba la explotación anglosajona e invitaba a forjar el mestizaje.

Los sandinistas proclamaban su devoción a los valores tradicionales y nacionales que debían responder a las reivindicaciones históricas del pueblo autóctono de la Nación nicaragüense. Cabezas extrapola su identidad individual hacia la colectiva dando la verdadera paternidad de toda "nuestra" historia en Sandino -mito-. Además, ve en él su génesis, raíces, antepasados: su herencia indígena. Le otorga a este personaje un contenido simbólico y el sentido para quienes se identifican con su causa o se colocan fuera de ella.

Como sandinista, Cabezas se percibe a sí mismo y percibe a sus compañeros como depositarios de un "verdadero" ser que los hace "distintos" de otros. La definición del sí mismo o del "nosotros" implica una distinción con los valores, características y modos de vida de otros. Hay un claro mecanismo de oposición al "otro". Así, del texto surge la idea del "nosotros", los seguidores del sandinismo, en cuanto opuesto a "ellos" o a los "otros", la Guardia y los seguidores del gobierno somocista y aunque los dos están sometidos al 
entrenamiento militar, el de Cabezas es mejor -juicio de valor- porque está sucediendo en la montaña. Aquí el "otro" no es aquel que vive fuera, el bárbaro o primitivo sino aquel que pertenece y practica un sistema político diferente. Existe una posición clara en cuanto al mensaje político intencionado que da un carácter normativo y doctrinario (componente ideológico).

Castells (1998:30) plantea que toda construcción social de la identidad siempre tiene lugar en un contexto marcado por las relaciones de poder. De modo que propone tres formas y orígenes de construcción de la identidad, cuya combinación es perfectamente factible, a saber:

1. Identidad legitimadora: introducida por las instituciones dominantes de la sociedad para extender y racionalizar su dominación frente a los actores sociales.

2. Identidad de resistencia: generada por aquellos actores que se encuentran en posiciones / condiciones devaluadas o estigmatizadas por la lógica de la dominación, por lo que construyen trincheras de resistencia y supervivencia basándose en principios diferentes $\mathrm{u}$ opuestos a los que impregnan las instituciones de la sociedad.

3. Identidad proyecto: cuando los actores sociales, basándose en los materiales culturales de que disponen, construyen una nueva identidad que redefine su posición en la sociedad y, al hacerlo, buscan la transformación de toda la estructura social.

Es claro que muchos fragmentos de Cabezas se sitúan en el segundo tipo de construcción identitaria tipificado por Castells.
La construcción identitaria no se basa en las sociedades civiles (iglesia, sindicatos, partidos, cooperativas...) que han perdido credibilidad en la conciencia de la gente sino como una prolongación de la resistencia comunal. Así, ve en el sandinismo una institución secundaria que transmite y produce sentido, como complemento de las instituciones civiles y estatales que han perdido fuerza. En su personaje -don Leandro- ve la encarnación de "la historia del pueblo de Nicaragua... una historia de rebelión contra la explotación, contra el dominio norteamericano, interpretado de una forma sensorial y primitiva por ellos, tenían un sentimiento histórico de rebeldía adquirido de su enfrentamiento con la ocupación norteamericana. No era irresponsabilidad, sino la historia, la vergüenza del pueblo, la rebeldía histórica del pueblo".

Y, aplicando los mismos tipos de construcción identitaria de Castells a Liano, tenemos que hay una combinación de los dos primeros.

\section{Una sociedad urbana y rural al amparo del militarismo y la violencia}

En todo momento, Cabezas evade las acciones armadas que tuvieron como concreción el espacio geográfico, luchas crudas con la Guardia en la lucha de poder. Únicamente, transporta al lector a la formación ideológica del movimiento sandinista ubicando al Che Guevara como una figura orientadora, motivadora y representante de una iconografía estable. Menciona Pérez (s.f) que dicha evasión corresponde a las formas de pensamiento propias de la mística revolucionaria y, además, sirve para sustentar el objetivo de "educar" para 
el futuro, para transformar hombres normales en hombres nuevos: situación bastante diferente al abordaje de Liano.

\section{"Nosotros", los militares: cirujanos y padres de una sociedad}

El hombre de Montserrat, ese bulto que se encontró a un lado de la carretera el teniente García, es uno de los miles de cuerpos tirados al lado de las carreteras cuyo asesino real queda impune. La obra se articula desde la perspectiva masculina del militar, en la cual García representa a los miles de militares; es una voz individual que perfectamente se extrapola a la colectiva, de los mismos militares. Por otra parte, representa a un grupo hegemónico que reprimió, que hizo y deshizo. Además, representa al grupo privilegiado que era visto como: "Un amigo en el ejército, decía equivocándose, [Matamoros a García]era mejor que una cuenta en el banco (p. 77).

El sentido de pertenencia en la persona de García se refleja en un "nosotros", como un grupo social heterogéneo en sus actitudes y en las funciones que cumple en la ciudad y en el campo. "Nosotros" los militares, equiparados con el buen médico, quien extirpa el órgano infectado para que el cuerpo sano pueda vivir: "Nosotros somos los cirujanos de este país. Y si nosotros no se lo hacemos a ellos, ellos nos lo harán a nosotros. Así son los comunistas. ¡O ellos o nosotros!” (p. 117).

Utilizando la táctica "tierra arrasada", el cinismo salta a la vista en la lectura; así, puede verse que el oficio del militar era muy cansado ¡Pobres!: "Porque matar gente cansa. Al principio tenía la diversión de lo nuevo; luego, repitiéndolo, cansaba como todo oficio. Para los soldados, matar indios se había vuelto una tarea fastidiosa como cualquier otra del servicio militar" (p. 118). ¿Quién no lo estaría después de esto, de arrasar hasta las raíces en su más amplio sentido, tal y como desconcertadamente se expone en las páginas 116 y $117 ?$ :

Los indios se habían encerrado en los ranchos. Los sacaron a todos a la plaza. Tenían los ojos vidriosos de temor. Los soldados les gritaban, los empujaban, los pateaban. Ellos obedecían con las quijadas temblerequeantes, con el rostro terroso, con las canillas que les flaqueaban. No parecen animales porque el animal acorralado se defiende, muestra los dientes, saca las garras. La gente en cambio, se vuelve toda ojos, toda súplica, un puro nudo de angustia y asqueroso terror.

García apenas daba órdenes. El ritual era el mismo y los soldados ya estaban habituados. Gestos. Chasquidos. Guiños. El sargento llamó a cinco de una lista que les habían preparado en la base.

No hubo modo de saber nada. Los nombres de la lista correspondían a gente denunciada por infiltrados o por informadores o por simples denunciantes. El sargento les gritaba, preguntándoles si estaban metidos en la mierda.

-Aquí están, miren! —insistía¡aquí está tu nombre, ve! En la mierda están ustedes y mejor si me lo van 
diciendo chanín, y quién del pueblo los ayuda, pero ve: rápido, que me estoy cansando!.

Parecían idiotas. Decían que no, pero tal era el miedo que no convencían a nadie. Los amarraron. Los rociaron de gasolina. Les prendieron fuego. La gente del pueblo se estremeció como con un temblor, mientras los cinco de la lista caían al suelo, gritando y achicharrándose.

— ¡Ora me lo dicen! — gritó el sargento - iya vieron lo que le pasa a los subversivos! Ora me dicen quién está metido en la mierda, si no, nos los soplamos a todos...

Ya la gente comenzaba a suplicar, y esto desagradaba a García. Se dirigió al grupo:

-No, señores. Con rogar no se gana nada. Aquí o hablan o se mueren. Gente hay de sobra en el mundo y de la mierda no debe quedar pero ni la semilla, ¿me oyeron? ¡ni la semilla!

Los soldados se enfurecían al ver la sangre. La gente gritaba y eso a ellos más bravos los ponía. Separaron hombres de mujeres. A unos los metieron en una casita, que servía de escuela y juzgado. A las otras, en una iglesia protestante. Luego, los mataron a todos. Con arma blanca, para no desperdiciar plomo ${ }^{3}$. Había un detalle que siempre le llamaba

3 Tal como dijo el jefe de la Policía, sólo un buen principiante se pone nervioso y llena de plomo a su víctima (p.76). la atención al teniente García: la cantidad de sangre que contiene un cuerpo. Litros y litros. Al final, en la escuelita, se había formado una poza.

Cuando no quedó nadie vivo, le prendieron fuego a la aldea. Cuando los guerrilleros llegaran, debían darse cuenta de que habían perdido una base.

\section{$[\ldots]$}

Rápido prendía fuego la madera. Las láminas se encartuchaban $\mathrm{y}$ caían ruidosamente en medio del chisperío y el humo negro. La pestilencia era insoportable. Algunas gallinas pasaban corriendo con las plumas empapadas en sangre. El escándalo del incendio se sobreponía al ruido natural de la selva.

La tropa agarró camino de regreso. Iban sudorosos, colorados, con la espalda iluminada por el resplandor de las llamas. No iban alegres, sino descargados. Cantaban en voz baja una canción del cuartel, para darse ánimos, y sobre todo, para olvidar el cansancio. Iban cansados, muy cansados. (pp. 116-117)

El "castigo" de dos años en la selva que vivió García, como "oficial de montaña" tan común en Guatemala, por un crimen en el que supuestamente encubría a su cuñado pero que éste no cometió, recuerda que los militares han servido como soporte del poder personal de los dictadores; sin embargo, al margen del ejercicio del poder 
político. Tampoco en la lucha en el campo, los militares salen ilesos.

\section{Los “otros", los asesores extranjeros: amenazantes de la territorialidad}

El uso social de un espacio marca los bordes dentro de los cuales los usuarios "familiarizados" se autorreconocen y por fuera de los cuales se ubica al extranjero o, en otras palabras, el que no pertenece al territorio. Así, un territorio se reconoce en virtud de la visita de un extranjero, quien bajo distintas circunstancias ha de ser indicado como por fuera del campo respectivo. El territorio se "territorializa" en la medida en que estrecha sus límites y excluye la presencia extranjera. Esto ocurre en momentos de alta peligrosidad, de tensión o desconfianza cuando el extranjero se "delata" en su aparecer inapropiado porque desconoce los códigos de auto-reconocimiento de los habitantes del territorio en cuestión (Silva, 1998:53).

La territorialidad alude más bien a una complicada elaboración simbólica que no se cansa de apropiar y volver a nombrar las cosas en característico ejercicio existencial-lingüístico: aquello que vivo lo nombro; son las sutiles y fecundas estrategias del lenguaje.

Volviendo a la novela de Liano, de acuerdo con la forma de nombrar pueden reconocerse dos tipos de "otros" ligados a este nosotros, que a simple vista parecerían conformar un solo grupo cohesionado. Uno, representado por los asesores extranjeros, fiel reflejo de la arrogancia impuesta por Estados Unidos en Guatemala y en muchas partes del mundo, que todavía hoy sigue apostando a las "limpiezas". García pensó: “... que para el asesor daba lo mismo Guatemala o Salvador o Medio Oriente. Lo principal era echar riata" (p. 47). También, eran los encargados de formar la capa hegemónica bajo normas que aplicarían a otros grupos; recuerda el teniente García que: "en el curso de Rangers. Allí los gringos cabrones no los dejaban dormir: simulaban una emboscada y los dejaban morados de la pijaceada" (p.107).

En la ciudad, bajo la mampara de la " $a c$ ción cívica", asesorada y financiada por la asistencia militar para el desarrollo por parte del país del norte, los programas de desarrollo local para la población son diseñados y ejecutados por las fuerzas armadas. La dulce labor de desarrollo local fue acompañada por la amarga tarea de lucha contra el enemigo interno: el comunismo, el terrorismo, la subversión.

Durante los largos años de lucha de liberación y de emancipación, de lucha del anticomunismo, de la ley y de la estabilidad nacional, de acuerdo con la posición de quien afirme una de estas dos suposiciones, la población aprendía a ser cautelosa, a expresarse con cuidado, a comportarse con sospecha:

"Ya vas a ver", le dijo el asesor. "Las casas guerrilleras van a ir cayendo una tras otra". Estaba contento, como si le importara la cosa. "Con razón ganan todas las guerras', pensó García, admirado de la eficiencia militar del otro" (p. 87)

Aunque en Liano más que en Cabezas, en el espacio se creó gradualmente 
-parcialmente escondida y parcialmente abierta- una completa maquinaria de control, persecución, opresión y matanza, aparentemente dirigida contra la guerrilla en el campo, pero en el transcurso de los años gentilmente amplificada hacia todos los segmentos de la sociedad civil rurales y urbanos. Torturar, desaparecer, violentar, masacrar fueron percibidos como medida correctiva y educativa para la estrategia de combatir y de prevenir, de terror y de detenimiento (Kruijit, 2000: 51).

Kruijit (2000:49) argumenta que los efectos económicos, sociales y políticos de la lucha de insurgencia y de contra-insurgencia quedaron limitados a un nivel local o regional. Sin embargo, las consecuencias para la sociedad nacional fueron nefastas: la sociedad guatemalteca comenzaba a transformarse durante la lucha antisubversiva en una sociedad de terror y de miedo. Los estamentos militares utilizando el pretexto del "peligro comunista" produjeron y reprodujeron gradualmente un régimen político cívico-militar de violencia y de represión.

En un país en que impera la violencia, los militares se ubican en la cúspide de la pirámide social: (¡Aqui el ejército es el papá de todo el mundo!) Recuerda el jefe de García. En contraposición, un segundo "otro" se compone de los "orejas".

\section{Los "otros", los orejas: desterritorializados y lamidos}

En García se construye una persona que se jacta de la superioridad psicológica e instrumental de los militares respecto a la policía. Ser militar es "cosa de hombres"; se sentía orgulloso de la diferencia que había entre el ejército y la policía: "mientras nosotros trabajamos con computadora, éstos todavía joden a la gente con candela..." En Cabezas, el "nosotros" son los sandinistas y los otros, es la Guardia Somocista también denominada los orejas. Y, en esta última obra, la cosa de hombres es ser sandinistas.

En El hombre de Monteservat, los valores en juego manejados, los mejor posicionados, eran los relacionados con la modernización, que propugna el progreso, el ascenso social, el éxito. Se refiere a ellos como "sicarios" y utiliza la metáfora de un trapo percudido para referirse a la sede de la Policía (Judicial), centro de trabajo: "era un edificio chato, de un piso y de color verde acuoso descuidado" (p.65).

Varias veces a lo largo de la obra, Liano deja entrever a unos militares muy indefensos, inocentes, incapaces de causar ningún mal y dejando en un pésimo lugar y descalificación total a la Judicial. Quizás, pueda hacerse una lectura de ridiculización simultánea de dos grupos dominantes de la sociedad; el autor los está desestructurando de su identidad tradicional. Queda evidenciada la propia percepción acerca de lo que consideraban una sociedad competitiva, individual e hipócrita. Si por identidad se entiende el acto en que un individuo se define, se clasifica, identificándose con un grupo y al mismo tiempo diferenciándose de otro, entonces, se tienen posiciones diferenciadas, que producen percepciones distintas de la realidad y de la sociedad, de los valores en juego. 


\section{Otros discursos identitarios en un espacio que se globaliza}

\section{La mujer en el espacio público y privado: entre "amas de casa" y guerrilleras}

Tradicionalmente, la narrativa guatemalteca se ha caracterizado por su falta de erotismo, asociada a rasgos ideológicos del catolicismo. Lo que hay es machismo: el hombre en la calle, en las cantinas, el dominante. Y la mujer, en la casa, en la cocina, de servidora doméstica, "ama de casa", sentimental. Las pocas narraciones sobre mujeres en la novela hacen referencia a la mujer que gritaba llorando por su hijo en la Policía, a la esposa y a la amante de García, también en momentos de llanto.

En Cabezas, el discurso es esencialmente masculino; se trata de una novela hecha para, por y de hombres. La figura femenina - excepto por la montaña- nunca juega ningún papel importante. Ni madres, ni amantes, ni compañeras, están siquiera en un plano segundo. Más bien, es una masculinidad alternativa casi homosexual. En La montaña..., el amor entre hombres llena más, es más completo (dentro del relato de vida) porque lleva solidaridad, ternura, entrega, sinceridad, apertura y algo de erotismo: "Nos tratábamos toscamente pero en el fondo nos amábamos con un amor profundo, con una gran ternura de hombres. Un grupo de hombres abrazados, hermanados, éramos un grupo de hombres con un beso permanente entre los mismos" (Cabezas, 1999: 105).

Pérez (s.f.) argumenta que en esta obra, el orden es "patrilineal": hijos de Sandino, hijos de don Leandro o cuando Cabezas dice que sentía que renacía, al darse cuenta de que él era fruto de una continuidad sandinista. Habiéndose separado ya de la montaña (del principio femenino) se identifica con el padre, o mejor dicho, con los padres de la nueva patria, una cadena de padres que conectan al narrador con Sandino mismo, con el fundador de la nueva nación.

\section{Los medios de comunicación: signo de globalización y posmodernidad}

En ambas novelas, los medios de comunicación cubren, encubren y descubren. Se desarrolla un discurso que pertenece al universo de las imágenes visuales y al de la informática. Por ejemplo, en Liano cuando el ejército asaltó la casa de seguridad ubicada en una zona residencial, un noticiario televisivo cubrió el espectáculo en medio de la muerte y la Coca Cola, el refresco de la vida. Esta teletransmisión de los acontecimientos se relata de una manera ágil y totalizadora, como la imagen televisiva (desde la página 46 a la 62). Pero lo interesante es, además, que la ubicación de la casa de seguridad se logró gracias a la utilización de la informática, localizando las casas y locales donde los consumos de energía eléctrica y agua fueran más altos de lo normal.

\section{Los estudiantes universitarios: creadores de conciencia}

En ambas novelas, los estudiantes universitarios funcionan como germinadores y difusores de conciencia mediante el conocimiento y las nuevas ideologías. En la ciudad, se encargan de la organización de las principales "cabezas" y, en el campo, 
son formadores, dispersores ideológicos y de aplicación de conocimientos que a los estudiantes como "urbanitas" les generan un alto costo.

\section{La iglesia: pastoral liberadora especialmente en el campo}

En un diálogo entre García y el general, el superior del primero comparaba el poder de la Iglesia con el del ejército. La consideraba tan fuerte como éste y calificaba a los "curas" como "sotanudos, intrigantes, plirazos" (p. 113). La solidez de la Iglesia radicaba en un apoyo de la jerarquía al fortalecimiento del aparato eclesiástico con el aporte del clero extranjero. No obstante, en comparación con la situación hegemónica en otros países de la región, el ejército siempre minó a la Iglesia (Samandú y otros, 1990: 69, 36).

En el caso guatemalteco como en el nicaragüense, junto a los sectores populares, la Iglesia también tuvo que soportar los embates de la represión. Entre 1978 y 1985 fueron asesinados cinco sacerdotes diocesanos, ocho sacerdotes-religiosos y dos religiosos no sacerdotes, de los cuales once eran extranjeros y cuatro guatemaltecos, además del secuestro de numerosos religiosos y sacerdotes (55). Entre el 10 de enero de 1980 y el 10 de agosto de 1981, abandonaron el país 91 sacerdotes y 64 religiosas, quedaron destruidas o silenciadas seis emisoras católicas y dejaron de funcionar diez colegios católicos y 42 centros de formación religiosa (Samandú y otros, 1990: 60). Sin embargo, el papel gravitante de la Iglesia fue en las zonas rurales, entre 1970 y 1984, donde florecieron múltiples y ricas expresiones de pastoral liberadora.
En Guatemala, uno de los blancos preferidos de la represión fue el laicado: miles de catequistas, delegados de la palabra y animadores de comunidades perdieron su vida, a la vez que muchos de los desplazados, refugiados y desaparecidos eran católicos. No solamente la represión física golpeó a la Iglesia, también todo el sistema de control limitaba mucho su trabajo. Los polos de desarrollo, donde fueron ubicadas alrededor de 50000 personas, prácticamente se cerraron para los agentes de pastoral; en las áreas de conflicto, sacerdotes y laicos debían tener en cuenta a los informantes de los militares sobre el contenido de las homilías y de las reuniones de reflexión, siendo necesario, en muchos lugares, solicitar permiso para realizar actividades pastorales. Todo ello dificultó enormemente el trabajo pastoral en los lugares donde todavía quedaban agentes y debilitó la presencia de la Iglesia institucional en vastas regiones del país, lo cual dejó sesenta parroquias sin párroco y a miles de creyentes sin atención pastoral.

\section{Las reformas agrarias: socialización del espacio}

Uno de los componentes estratégicos de la revolución sandinista fue transformar las relaciones con la propiedad. La reforma agraria constituyó el principal instrumento para llevar adelante las transformaciones en el agro. Las alusiones, en este sentido, son numerosas.

Torres-Rivas (1993:148) expresa que la vía sandinista de cambios agrarios no constituyó tampoco una experiencia clásica de reformismo campesino. Aunque hubo una reorganización cooperativista 
más que distribución de tierras, tampoco puede despreciarse que entre 1981 y 1988 , más de 77000 familias se beneficiaron de la entrega de tierras.

\section{Conclusiones}

En apariencia, una novela sencilla pero hay juegos, analepsis. Mediante los sueños, García hace retrocesos y adelantos en el tiempo y el espacio. Es inexistente un solo espacio cronotópico, vuelve al colegio... y la selva.. Tal parece que en El hombre de Montserrat es parte de la nueva narrativa guatemalteca donde se mantienen los "temas discursivos" pero con una significativa evolución en el plano discursivo, entre otros, brevedad del relato, aún dentro de las normas convencionales de la forma novelesca. Documentación conciente de una multiplicidad de voces discursivas que tradicionalmente eran consideradas marginales y rara vez habían protagonizado textos en períodos anteriores. Novelas abiertas, carentes de forma, cuya estructura está compuesta fundamentalmente de una multiplicidad de fragmentos.

Las nuevas tendencias de la narrativa guatemalteca se articulan con otros procesos simbólicos extraliterarios de búsqueda de reestructuración del sentido y de redefinición de la identidad del guatemalteco -así como de sus límites y contradicciones teóricas e ideológicas-, tanto en el ámbito maya como en el ladino. Todo esto es parte de un proceso de descomposición social en el nivel nacional y de diferentes intentos por rearticular un espacio ideológicointegrativo que incorpore a los diferentes sectores sociales dentro de una visión nueva de Estado.
Mackenbach se pregunta si la literatura centroamericana presenta una transmutación de valores en las últimas décadas, donde dominan los discursos político-militares. Estas dos novelas son claros ejemplos de discursos militares y políticos, desde dos ópticas diferentes.

Afirmar que la geografía sirve fundamentalmente para hacer la guerra no significa sólo que se trata de un saber indispensable para quienes dirigen las operaciones militares. No se trata sólo de desplazar a las tropas y sus armamentos una vez iniciada la guerra; se trata, asimismo, de prepararla, tanto en las fronteras como en el interior, de elegir el emplazamiento de las plazas fuertes, de construir varias líneas de defensa y de organizar las vías de circulación: el territorio con su espacio y su población no es únicamente la fuente de toda fuerza militar sino que también forma parte integrante de los factores que actúan sobre la guerra, aunque sólo sea porque construye un teatro de operaciones.

Son las acciones y los pensamientos humanos los que dan sentido a una porción cualquiera del espacio y la convierten en territorio. En este sentido, los discursos de ambas novelas dejan el sabor de una organización con poder político que impregnó el espacio y a los hombres desde el punto de vista psicológico como social, económico y demográfico. Todo sentimiento de deseo y de control es una expresión humana de la territorialidad. En ambas novelas, la territorialidad se practicó a través de la violencia y el control; fue una forma de comportamiento espacial, un acto de intencionalidad, una estrategia con tendencia a afectar, influir o controlar a la gente y los recursos de un territorio. 


\section{Bibliografía}

Albertani, C. (1997). Escribir es recordar, una plática con Dante Liano. Entrevista realizada en enero de 1997. Milán, Italia. www.calu-01.hmtl

Alvarado, L. El proceso de urbanización en Guatemala: Revista Geoistmo, volumen 11, número 2, 103-118. Revista de la Asociación de Profesionales en Geografía de Costa Rica. Instituto Geográfico Nacional y Departamento de Geografía, Universidad de Costa Rica.

Arias, A. (1998). La identidad de la palabra. Narrativa guatemalteca a la luz del siglo XX. Guatemala: Editorial Artemio-Edinter.

Bajtín, M. (1994). El método formal en los estudios literarios. Madrid: Alianza Universidad.

Berger, P. y Luckmann, T. (1997). Modernidad, pluralismo y crisis de sentido. La orientación del hombre moderno. Barcelona: Piados Studio.

Cabezas, O. (1999). La montaña es algo más que una inmensa estepa verde. La Habana: Txalaparta.

Carreras, C. (1998). El uso de los textos literarios en geografía. En: Aurora García Ballesteros, A. Métodos y técnicas cualitativas en geografía social. Barcelona: Editorial Oikos-Tau.

Castells, M. (1998). El poder de la identidad. Vol. 2. La era de la información. Madrid: Alianza Editorial.

Consejería de Educación y Ciencia. Londres. Donaire, 12. Creación: Dante Liano. www.conseduca.lon@dial.pipex.com

Gaínza, G. (1988). Herencia, identidad y discursos. Herencia, 1, 1, 53-58.
Galeano, E. (1992). Ser como ellos y otros artículos. México: Siglo XXI.

Galich, F. (s.f.). El hombre de Montserrat, de Dante Liano: ¿Novela de la posmodernidad en Guatemala? Inédito.

García Escobar. El vuelo del ángel. Periódico La Hora. Nueva Guatemala, 21 de setiembre de 1996. En: www. sololiteratura.com.

Gould, J. (1995). Nicaragua: La nación indohispana. En: Taracena, A. y Piel, L. (compiladores). Identidades nacionales y Estado moderno en Centroamérica. San José: Editorial Universidad de Costa Rica. Colección Istmo.

Herrera, B. Literatura y geografía. Divertimento fronterizo. En: García E. Fronteras: Espacios de encuentros y transgresiones. San José: Editorial de la Universidad de Costa Rica. Colección Identidad Cultural.

Kruijt, D. (2000). Baile de disfraces: Ensayos sobre viejos y nuevos actores en la sociedad militar y la sociedad civil de América Latina. San José: FLACSO.

Liano, D. (1994). El hombre de Montserrat. México: Editorial Aldus. Colección La torre Inclinada.

Mackenbach, W. Historia, nación/pueblo $e$ individuo en el testimonio nicaragüense y centroamericano. Universidades de Frankfurt y Postdam. En: www.wooster.edu/istmo.

(2002). Espacio urbano y espacio literario en tres novelas centroamericanas contemporáneas. Universidades de Frankfurt y Postdam. Congreso Internacional de Literatura Centroamericana. Berlín, Alemania, 23-24 abril. 
Pérez Cuadra, M.S. (s.f). El testimonio como "fin” y ficción. Managua: Universidad Centroamericana www. mperez_cuadra@hotmail.com

Rosada-Granados, H. (1999). Soldados en el poder: Proyecto militar en Guatemala (1944-1990). San José: Fundapem.

Samandú, L. Sierra, O. y Siebers, H. (1990). Guatemala: los retos de la Iglesia Católica en una sociedad en crisis. San José: Editorial DEI.

Silva, A. (1998). Imaginarios urbanos. Cultura y comunicación urbana. $3^{\mathrm{a}}$ ed. Santafé de Bogotá: Tercer Mundo Editores.
Strahler, A. y Strahler, A. (1994). Geografía física. $3^{\mathrm{a}}$ ed. Barcelona: Ediciones Omega.

Torres-Rivas, E. (editor) (1993). Historia general de Centroamérica. España: Ediciones Siruela, Sociedad Estatal Quinto Centenario y Facultad Latinoamericana de Ciencias Sociales.

Varela, R. Entrevista con Omar Cabezas, 1989. En: información@culturas.com

www.laprensahn.com/caarc/9608/ c16004.htm. 